\title{
Nachruf
}

\section{Hans Becker}

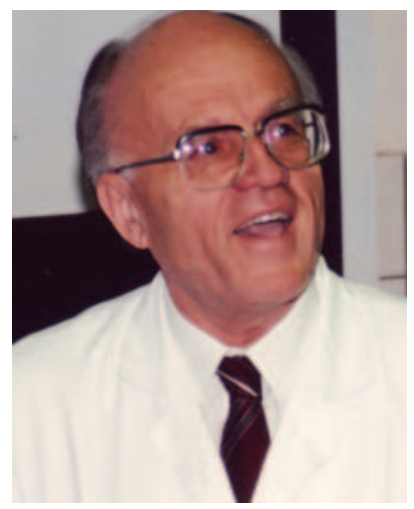

Im Mai 1960 erlebte ich als Zwölfjähriger die Promotion von Hans Becker sub auspiciis praesidentis rei publicae. Ich war sehr beeindruckt, und mit mir ganz Graz. Bundespräsident Adolf Schärf war eigens angereist, und die Zeitungen berichteten über das Flüchtlingskind, das diese damals noch sel-

tene akademische Ehrung bekam.

Hans Becker wurde 1930 in Belgrad als Sohn einer deutschen Mutter und eines russischen Vaters geboren. Nach dessen frühem Tod starb die Mutter an den Folgen einer Gallenblasenoperation als Hans zehn Jahre alt war. Zwei Tanten sorgten für ihn, und er teilte ihr Schicksal in dem Chaos von Krieg, Vertreibung, Flucht und Neubeginn. Wie so viele, die das Schicksal von displaced persons teilten, schwieg er zeitlebens über seine Erlebnisse. Die Internatsschule und das Medizinstudium absolvierte er mit Bestnoten. In den Ferien verdiente er sich in Stahlwerken und Erzgruben ein Zubrot und entdeckte das Bergsteigen im Gesäuse, in den es einen Teil der versprengten Familie verschlagen hatte.

Hans Becker wurde 1958 Assistent unter Max Ratzenhofer am Institut für Pathologie der Karl-Franzens-Universität und habilitierte 1970. Er gründete und leitete die Abteilung für Kinderpathologie und beschäftigte sich intensiv mit der pathologischen Anatomie der Leber und von Lymphomen.

Trotz seiner kargen Jugend hatte sich Hans Becker eine Heiterkeit bewahrt. Gegen Ende seiner schweren Erkrankung erschien sie etwas mit Galgenhumor gewürzt, aber welcher Humor wäre dem Pathologen adäquater? Er war überzeugt, dass eher Anlage und nicht so sehr die Umwelt den Charakter prägten. Seine Heiterkeit angesichts der Entbehrungen der Jugend könnte ihm Recht geben. Seine Liebe zum Bergsteigen, aber auch zuletzt seine schneidige Einstellung zu der belastenden und riskanten Therapie des Lymphoms bei - das war ihm bekannt - lediglich aufschiebender, nicht kurativer Wirkung, diese Einstellung hatte etwas vom Sentiment eines Haudegens. Schimmerte in dieser Schneid sein Vater durch, von dem wir wenig wissen, ein Offizier - displaced nach einem verlorenen Bürgerkrieg?

Das Risiko, noch mal fremd zu sein, wollte er nicht eingehen. Er blieb in Graz und lehnte lukrative Angebote im Ausland ab. Bis zuletzt führte er ein angeregtes und ausgefülltes Leben, und war bis weit nach der Pensionierung im Bereiche der ärztlichen Direktion des LKH Graz tätig. Hans Beckers besonderes Engagement galt dem Wissenschaftlichen Verein der Ärzte und Naturforscher für Steiermark und Kärnten, dem er in leitender Position bis zuletzt angehörte. Das Land verlieh ihm das Große Goldene Verdienstkreuz für Wissenschaft und Forschung.

Univ.-Prof. Dr. Hans Becker ist am 7. Januar 2010 nach kurzem schwerem Leiden an einem Angioimmunoblastic T-cell Lymphoma (AITL) verstorben. Die Diagnose, eines der aggressivsten Lymphome, war ihm von Diagnosestellung an in ihrer vollen Bedeutung bewusst. Er hinterlässt eine Frau, drei Söhne und sechs Enkelkinder.

Johannes Miholić, Wien

\section{Interessenskonflikt}

Es besteht kein Interessenskonflikt. 